Vol III. No.2, Maret 2019, hlm. 160 - 167

Available online at www.jurnal.una.ac.id/indeks/jmp

\title{
MODEL PERENCANAAN JARINGAN TRANSPORTASI DENGAN ADANYA TRANSFER
}

\author{
Rahayu Sashanti \\ Dosen Teknik Elektro Universitas Prima Indonesia \\ Email: rahayusashanti.rs@gmail.com
}

\begin{abstract}
Transportation route planning problems determine from a transport mode can be simplified by using network model, which can be represented by graph theory. This important component of the transportation network planning is finding the shortest path. In this thesis will learn how to find the model of a transportation network planning using the shortest path with best path algorithm. This algorithm trying to find the itinerary that requires the least number of transfers. It can be a model of path network transportation with transfer. The used model was the model with matrix.
\end{abstract}

Keyword: Public transportation, Shortest path, Best path algorithm.

\begin{abstract}
Abstrak
Permasalahan menentukan perencanaan rute transportasi dari suatu moda transportasi dapat disederhanakan dengan menggunakan model jaringan, yang kemudian dapat direpresentasikan dengan teori graf. Komponen penting dari perencanaan jaringan rute transportasi adalah menemukan lintasan terpendeknya. Dalam penelitian ini akan mempelajari bagaimana menemukan model perencanaan jaringan transportasi dari suatu lintasan terpendek dengan menggunakan algoritma best-path planning. Algoritma bestpath planning berusaha menemukan rencana perjalanan yang membutuhkan paling sedikit jumlah transfer. Model ini akan dirancang menjadi model perencanaan jaringan transportasi dengan adanya transfer. Model yang digunakan adalah model yang menggunakan matriks.
\end{abstract}

Kata kunci : Transportasi publik, Lintasan terpendek, Algoritma best-path planning. 
Vol III. No.2, Maret 2019, hlm. 160 - 167

Available online at www.jurnal.una.ac.id/indeks/jmp

\section{PENDAHULUAN}

Masalah transportasi merupakan masalah yang selalu dihadapi oleh negara-negara yang telah maju dan juga oleh negaranegara yang sedang berkembang. Seperti di negara Indonesia untuk bidang transportasi perkotaan maupun transportasi antar kota dapat tercipta suatu sistem transportasi yang menjamin pergerakan manusia/barang secara lancar, aman, nyaman yang merupakan tujuan dari sektor transportasi. Untuk wilayah perkotaan, transportasi memegang peranan yang cukup menentukan. Suatu kota yang baik, antara lain dapat ditandai dengan adanya transportasi yang baik, aman, lancar yang mencerminkan keteraturan kota dan kelancaran kegiatan perekonomian kota (Liu, 2002).

Namun dewasa ini, masyarakat lebih banyak memilih untuk menggunakan kenderaan pribadi daripada transportasi umum. Dan semakin banyak masyarakat yang memilih untuk menggunakan transportasi pribadi akan berdampak semakin ramainya keadaan jalanan hingga melebihi kapasitas jalan yang disediakan sehingga me-ngakibatkan kemacetan. Berbicara transportasi pasti tak akan luput dari masalah kemacetan. Kemacetan juga menjadi masalah besar pada sektor transportasi yang mengakibatkan lamanya waktu perjalanan untuk sampai ke tempat tujuan dan boros biaya bahan bakar. Untuk mengurangi masalah kemacetan tersebut sudah sepantasnya masyarakat beralih ke transportasi publik sebagai sarana transportasi. Disisi lain, banyak juga alasan dan pertimbangan untuk tidak memilih menggunakan transportasi umum. Salah satu alasan yang lebih kuat untuk tidak menggunakan transportasi umum adalah kurangnya in-formasi tentang rute transportasi publik tersebut. Sehingga untuk menarik minat masyarakat agar bersedia beralih menggunakan transportasi umum, salah satu cara yang dapat dilakukan adalah dengan menyediakan informasi perencanaan rute ter-pendek transportasi umum untuk membantu penumpang merencanakan perjalanan mereka (Liu, 2002).

Permasalahan transportasi pada kota besar yang mempunyai jaringan transportasi yang rumit umumnya sama. Orang sering mengetahui rute perjalanan $\mathrm{ke}$ tempat yang biasa di kunjunginya, akan tetapi jika tempat tujuan tersebut belum pernah dikunjungi rata-rata sering kesulitan untuk menentukan rute untuk men-capai tempat tersebut. Selama ini orang akan bertanya kepada orang lain yang mengetahui betul jaringan transportasi di kota tersebut. Permasalahan di atas dapat diselesaikan dengan membuat suatu sistem yang dapat menjawab semua pertanyaan penumpang yang dapat menentukan jalur transportasi umum yang dikehendaki. Sistem ini sekaligus 
Vol III. No.2, Maret 2019, hlm. 160 - 167

Available online at www.jurnal.una.ac.id/indeks/jmp

dapat menentukan rute terpendek sehingga penumpang tidak perlu menempuh jarak yang jauh untuk mencapai tujuannya Lintasan terpendek merupakan lintasan paling minimum yang ditempuh dari suatu tempat untuk mencapai tempat tujuan tertentu. (Liu et al., 2001).

Untuk proses pencarian rute terpendek pada sistem transportasi umum perlu memperhatikan bahwa kenderaan umum hanya dapat melewati ruterute tertentu yang telah ditentukan sebelumnya, dan penumpang tidak dapat meminta pengemudi untuk mengganti rutenya. Banyak masalah perencanaan rute yang dapat diselesaikan dengan menghitung jarak rute terpendek menggunakan pemodelan yang cocok yangkemudian merepresentasikan-nya ke dalam jaringan transportasi. Pada transportasi umum, perlu diperhitungkan waktu yang diperlukan untuk melakukan transfer antar rute. Semakin banyak transfer antar rute yang dilakukan, maka se-makin banyak pula waktu dan biaya yang harus dikeluarkan oleh penumpang (Liu et al., 2001).

Untuk menghindari hal tersebut, digunakan suatu algoritma yang dapat memecahkan permasalahan lintasan terpendek yang diaplikasikan pada jaringan jalan. Solusi yang didapat dari penelusuran dari algoritma tersebut dapat diberi nama pathing algorithm. Dan salah satu algoritma yang tepat untuk permasalahan iniadalah algoritma best-path planning untuk menyelesaikan masalah pencarian rute terpendek pada transportasi umum dengan jumlah transfer seminimal mungkin sehingga penggunaan waktu menjadi lebih efektif dan permasalahan penumpang dapat teratasi (Liu et al., 2001).

Ada beberapa macam persoalan lintasan terpendek, antara lain adalah sebagai berikut:

1. Lintasan terpendek antara dua buah simpul tertentu (single pair shortestpath);

2. Lintasan terpendek antara semua pasangan simpul (all pairs shortest path);

3. Lintasan terpendek dari simpul tertentu ke semua simpul yang lain(single-source shortest path);

4. Lintasan terpendek antara dua buah simpul yang melalui beberapa simpul tertentu (intermediate shortest path). (Hsiao, et al ., 2004).

Dalam pencarian lintasan terpendek ada beberapa algoritma yang dapat dipergunakan. Dalam menyelesaikan persoalan lintasan terpendek masing-masing algoritma memiliki spesifikasi penyelesaian masalah, kompleksitas, waktu algoritma, serta jenis masalah yang berbeda. Dan disini algoritma yang digunakan adalah algoritma bestpath planning untuk menyelesaikan masalah pencarian rute terpendek pada transportasi publik dengan jumlah transfer seminimal mungkin sehingga penggunaan waktu menjadi lebih efektif dan permasalahan 
Vol III. No.2, Maret 2019, hlm. 160 - 167

Available online at www.jurnal.una.ac.id/indeks/jmp

penumpang dapat teratasi. (Bast, et al ., 2013).

Ada beberapa algoritma yang telah meneliti masalah perencanaan rute terbaik pada transportasi publik. Diantaranya adalah sebagai berikut:

1. Liu, et al, dalampath-planning algorithms for public transportation systems, menggunakanmatrikkonektivita s(connectivity matrices) yang merupakanpengembangandarim atrikkedekatan(adjacency matrices)untukmenyelesaikanmasalahbatasanjalurpadat ransportasipublik (Liu, et al., 2001);

2. Liu dalambest-path planning for public transportation systems, mempertimbangkanbahwa transfer antarrutepadatransportasipublik memerlukanlebihbanyakwaktud anbiaya,

menggunakanmatriktransisi(tra nsition ma-trices) untukmemperhitungkanjumlah transfer yang dibutuhkanolehpe-numpang (Liu, 2002);

3. Hsiao, et al., dalamant colony optimization for best path planning, menawarkanalgoritmasolusiberdasarkant eknikoptimasikolonisemut(ant colony optimization) untukmencariruteterpendekdari suatulokasiasalkelokasitujuanpa dapetadenganmempertimbangk ankondisilalulintas (Hsiao, etal.,2004);

4. Robert

GeisbergerdalamAdvanced Ruote Planning in Transportation Networks, membahasbanyakmasalahperencan aanrute yang dapatdiselesaikandenganmenghitu ngjarakterpendekmenggunakanpe modelan yang cocok, grafberbobot yang merepresentasikanjaringantranspor tasi. Padatrans-portasipublik, perludiperhitungkanwaktu yang diperlukanuntukmelakukan transfer antarrute (Geisberger, 2011).

\section{METODE}

Penelitian ini menganalisis penyelesaian masalah model transportasi publik untuk rute terpendek dengan menggunakan bantuan algoritma best-path planning untuk mengatasi permasalahan pencarian rute transportasi dengan proses transfer sehingga meminimumkan pencarian rute transportasi demi menghasilkan solusi terbaik.

Dengan demikian, prosedur yang dilakukan pada penelitian ini dapat ditulis :

1. Mengumpulkansegalainformasi dariberbagaireferensiliteratur yang ada, sepertidaribuku, artikel, paper, jurnalmengenaipemodelanpere ncanaanpencarianruteterpendek padajaringantransportasidengan adanya transfer;

2. Memahamidanmenganalisispen elitian-penelitian yang pernahdilakukanolehpeneliti

lain terdahulu yang berhubungandenganpenelitian yang di-lakukan;

3. Mempelajarimasalahgrafdanlint asanterpendek; 
Vol III. No.2, Maret 2019, hlm. 160 - 167

Available online at www.jurnal.una.ac.id/indeks/jmp

4. Mempelajarialgoritmabest-path planning;

5. Merancang model matriksuntukmembentuk model matematikaperencanaanpencari anruteterpendekpadajaringantra nsportasidenganadanya transfer

\section{HASIL DAN PEMBAHASAN}

Algoritma best-path planning merupakan algoritma yang diusulkan oleh Chao Lin Liu untuk mengatasi masalah pencarian rute pada transportasi publik dengan meminimalkan jumlah transfer antar rute untuk efisiensi waktu dan biaya. Algoritma ini ada untuk menemukan cara perencanaan perjalanan yang Pada algoritma berikut diasumsikan bahwa $i \in S R(O)$ dan $j \in S R(D)$. Algoritmanya adalah sebagai berikut:

1. Kasus sederhana: jika $O=D$, lokasi asal sama dengan lokasi tujuan, tidak perlu rute transportasi publik;

2. Rute langsung (tanpa transfer) : untuk setiap rute $r \in S R(O) \cup S R$ $(D) \neq 0$, jika $K(r, O)<K(r, D)$, dapat pergi dari $O$ ke $D$ melalui $r$;

3. Satu kali transfer: jika $T_{i, j} \leq 1, K(i$, $O)<K(i, s)$ dan $K(i, s)$ dan $K(j, s)$ i $K(j, D)$ berhenti di $s \in C S(i, j)$, dapat pergi ke $i$ melalui $O$, transfer dari $i$ menuju $j$ melalui $s$, dan sampai di $D$ melalui $j$;

4. Dua kali transfer: jika $T_{\mathrm{i}, \mathrm{j}}{ }^{2} \geq 1$ dan ada pemberhentian di $s \in C S(i, r)$ dan $\mathrm{t} \in C S(r, j)$, untuk rute $r \in$ $C R_{1}(i, j)$ seperti:

(a) $K(i, O)<K(i, s)$;

(b) $K(r, s)<K(r, t)$; dan

(c) $K(j, t)<K(j, D)$; membutuhkan transfer. Algoritma ini menggunakan $K(r, s)$ untuk menunjukkan nomor yang ditetapkan untuk berhenti adalah $s$ dan untuk rute adalah $r$. Ketika sebuah rute $r$ tidak berhenti di $s$, dengan menganggap $K(r, s)=0$. Algoritma ini juga mem-pekerjakan dua fungsi untuk relasi pemberhentian bus dan rute bus. Algoritma ini perlu untuk mengetahui rute layanan, $S R(s)$, bahwa bus berhenti untuk $s$. Dan algoritma ini perlu untuk mengetahui bahwa pemberhentian layanan bus oleh dua rute yaitu $r_{1}$ dan $r_{2}$ dan dinotasikan pemberhentian itu dengan $C S\left(r_{1}, r_{2}\right)$.

Kemudian dapat pergi ke $i$ melalui $O$, transfer dari $i$ menuju $r$ di $s$, transfer dari $r$ menuju $j$ di $t$, dan sampai di $D$ melalui $j$;

5. Tiga kali transfer: jika $T_{\mathrm{i}, \mathrm{j}}{ }^{3} \geq 1$ danadapemberhentian di $x \in C S(i$, $\left.r_{1}\right), \mathrm{y} \in C S\left(r_{1}, r_{2}\right)$, dan $z \in C S\left(r_{2}\right.$, $j)$ untuksuatupasanganrute di $\left(r_{1}\right.$, $\left.r_{2}\right) \in C R_{2}\left(r_{2}, j\right)$ seperti:

(a) $K(i, O)<K(i, x)$;

(b) $K\left(r_{1}, x\right)<K\left(r_{1}, y\right)$;

(c) $K\left(r_{2}, y\right)<K\left(r_{2}, z\right)$; dan

(d) $K\left(r_{2}, z\right)<K\left(r_{2}, D\right)$;

Kemudian dapat pergi ke $i$ melalui $O$, transfer dari $i$ menuju $r$ di $s$, transfer dari $r$ menuju $j$ di $t$, dan sampai di $D$ melalui $j$;

Algoritma ini mengecek tahapan demi tahapan apakah perjalanan bisa dilakukan hanya dengan rute langsung saja yaitu dengan menggunakan satu armada transportasi saja. Apabila tidak, maka dilakukan pengecekan ke tahapan 
Vol III. No.2, Maret 2019, hlm. 160 - 167

Available online at www.jurnal.una.ac.id/indeks/jmp

selanjutnya yaitu dengan sekali transfer saja, dan begitu pula selanjutnya sampai maksimal dapat dilakukan dengan beberapa transfer.

Langkah pertama benar jika asal dan tujuan berasal dari lokasi yang sama, dan memenuhi algoritma.

Langkah kedua dilakukan jika asal dan tujuan dilayani oleh sebuah rute layanan $r$. Jika iya, maka harus menguji apakah rute ini bergerak dari asal ke tujuan.

Langkah ketiga digunakan untuk perencanaan perjalanan yang memenuhi satu kali transfer dari rute $i$ ke rute $j$. Jika $T_{\mathrm{i}, \mathrm{j}}{ }^{\mathrm{k}}$ adalah positif, maka boleh men-transfer dari rute $i$ ke rute $j$. Kemudian harus memeriksa lokasi transfer berhenti $s$, dan pastikan bahwa ada kemungkinan untuk berpergian dari $O$ ke $s$ melalui rute $i$ dan dari $s$ ke $D$ melalui rute $j$ dengan mempertimbangkan nilai $K$ yang terlibat.

Langkah keempat dan kelima adalah dipergunakan untuk perencanaan per-jalanan yang membutuhkan dua dan tiga transfer, masing-masing. Untuk menemukan perencanaan yang membutuhkan $k$ transfer, harus memastikan bahwa $T_{\mathrm{i}, \mathrm{j}}{ }^{\mathrm{k}}$ adalah positif, dengan melihat $C R_{\mathrm{k}} 1(i, j)$ untuk ada kemungkinan menghubung-kan rute, dan memeriksa apakah terdapat ada lokasi dimana boleh mentransfer.

Algoritma ini bergantung pada nilai $K$ yang berhenti untuk memeriksa ke-layakan perencanaan perjalanan. Penugasan nilai $K$ bernilai implisit yang mengasumsikan bahwa semua rute layanan diarahkan dan asiklik. Tidak perlu mem-bandingkan nilai nilai $K$ dari dua pemberhentian di rute $r$ ketika lintasan dari $r$ membentuk lingkaran, karena bisa pergi antara setiap pemberhentian tersebut.

Dengan menggunakan prinsip yang sama, dapat memperpanjang algoritma ini untuk menemukan rencana perjalanan yang memerlukan lebih dari tiga transfer. Karenanya, algoritma selesai dalam arti bahwa dijamin akan menemukan rencana perjalanan yang cocok untuk perjalanan yang diinginkan ketika ada satu. Selain itu, karena algoritma ini memulai pencarian untuk rencana perjalanan dari orang-orang yang membutuhkan transfer yang lebih sedikit, algoritma ini optimal jika dalam arti bahwa dapat menemukan rencana perjalanan yang membutuhkan paling sedikit jumlah transfer.

Contoh Penerapan Algoritma best-path planning

Ilustrasi algoritma best-path

planning adalah sebagai berikut:

1. Kasus sederhana : Jika $A=A$, maka tidak bergerak, tidak ada rute perjalanan;

2. Kasus langsung (tidak ada transfer): jika $A \rightarrow D$, langsung dapat pergi dari $A$ ke $D$ melalui $r_{1}$;

3. Kasus satu kali transfer: jika $A \rightarrow B_{1} \rightarrow D$, pergi dari $A$ lalu transfer di $B_{1}$ lalu sampai ke tujuan $D$;

4. Kasus dua kali transfer : jika $A \rightarrow B \rightarrow C \rightarrow D$, pergi dari $A$ lalu transfer pertama di $B$, lalu transfer lagi di $C$ lalu sampai ke tujuan $D$;

5. Kasus tiga kali transfer : jika $A \rightarrow B \rightarrow C \rightarrow E_{1} \rightarrow D$, pergi dari $A$, transfer pertama di $B$, transfer 
Vol III. No.2, Maret 2019, hlm. 160 - 167

Available online at www.jurnal.una.ac.id/indeks/jmp

kedua di $C$, lalu transfer lagi di

$E_{1}$, dan sampai di tujuan $D$.

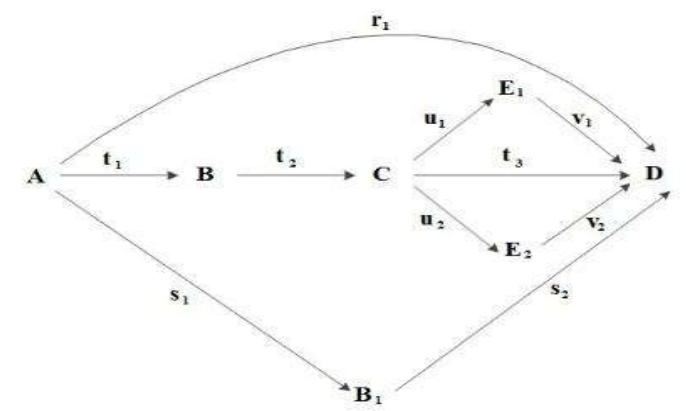

Gambar. Rute perjalanan dengan algoritma

\section{SIMPULAN}

Masalah

proses

pencarianperencanaanruteterpendekp

adasistem

trans-

portasiumumdapatdiselesaikandenga

nmenghitungjarakruteterpendek yang

memperhitungkanwaktuuntukmelaku

kan transfer antarrute. Salah satucaranyaadalahdenganmenggunak analgoritmabest-path

planningyangmerupakanalgoritma

\section{DAFTAR RUJUKKAN}

Bast,H., Carlsson, E., Eigenwillig, A., Geisberger, R., Harrelson, C., Raychev, V., dan Viger, F., (2010). Fast Routing in Very Large Public Transportation Networks Using Transfer Patterns. ESA'10 paper due to space limitations, Volume6346 of LNCS, pages 290-301, Springer.

Bast, H., Sternisko,J., dan Storandt, S., (2013). Delay-Robustness of Transfer Patterns in Public Transportation Route Planning. 13th Workshop on Al-gorithm Approaches for Transportation Modelling Optimization and yang berfungsiuntukmencariruteyang tersediadarisuatutempatketempatlain nyadenganjumlah transfer rutesesedikitmungkin.

Selanjutnyaakandiran-cangmenjadi model perencanaanjaringantransportasideng anadanya transfer. Model yang digunakanadalah model yang menggunakanmatriks. Denganbantuan matriks, algoritmabest-path planningberfokuspadaruteruteuntukmencariperencanaanperjala nan

yangbaiksehinggaberhasilmenemuka nruteterpendekdenganjumlah transfer paling sedikit. Untukmencarikemungkinan transfer rute,semuanyaberpusatpadamatrikstr ansisi yang telahada. Matrikstransisiituberfungsisebagaipe nentudari transfer rute yang mungkinada.

Systems (ATMOS'13, pages 4254.

Geisberger, R., (2011). Advanced Route Planning in Transportation Networks. PhD Thesis. Karlsruhe Instituts fur Technologie.Germany

Hsiao, Y.T., Chuang, C.L., dan Chien,C.C., (2004). Ant Colony Optimization forBest Path Planning. International Symposium on Communications and Infor-mation Technologies, Sapporo, Japan.

Liu, C. L. (2002). Best Path Planning for Public Transportation System. The 5thInternational 


\section{MATEMATICS PAEDAGOGIC}

Vol III. No.2, Maret 2019, hlm. 160 - 167

Available online at www.jurnal.una.ac.id/indeks/jmp

IEEE Conference on Intelligent Transportation Systems, 834839.

Liu, C.L., Pai, T.W., Chang,C.T., dan Hsieh, C.M., (2001). Path Planning Al-gorithms for Public
Transportation System. The Fourth International IEEEConference on Intelligent Transportation Systems Oakland, California, USA. 